Article

\title{
You Can't Beat Relating with God for Spiritual Well-Being: Comparing a Generic Version with the Original Spiritual Well-Being Questionnaire Called SHALOM
}

\section{John Fisher}

School of Education \& Arts, University of Ballarat, Victoria 3350, Australia;

E-Mail: j.fisher@ballarat.edu.au; Tel.: +61-3-438-395-915; Fax: +61-3-5327-9717

Received: 15 May 2013; in revised form: 27 June 2013 / Accepted: 28 June 2013 /

Published: 2 July 2013

\begin{abstract}
The Spiritual Health And Life-Orientation Measure (SHALOM) is a 20-item instrument that assesses the quality of relationships of the respondent with self, others, the environment and/or a Transcendent Other. In the Transcendental domain, four of the five items had the words 'God, 'Divine' and 'Creator' replaced by the word 'Transcendent' to make the survey more generic by removing any implied reference to any god or religion. Invitations to complete a web survey were sent to people who had published papers in spirituality, or belonged to associations for spirituality or religious studies, as well as the Australian Atheist Forum. 409 respondents from 14 geographic regions, completed the survey. Confirmatory factor analysis revealed that the modified, generic form of SHALOM showed acceptable model fit, comprising four clearly delineated domains of spiritual well-being. The paper analyses the results derived from using the modified, generic version and, in comparison with results of applications of the original survey instrument, concludes with discussion of the comparative utility of each of the versions of SHALOM. Further studies with more people are warranted, but, from evidence presented here, it looks like you can't beat relating with God for spiritual well-being.
\end{abstract}

Keywords: spiritual well-being; measures; God; SHALOM

\section{Abbreviations}

SWB: spiritual well-being. 


\section{Background}

It is not surprising that the concept God is pre-eminent in National Interfaith Coalition on Aging's [italics for emphasis] description of spiritual well-being as 'the affirmation of life in relationship with God, self, community and environment that nurtures and celebrates wholeness' [1]. By 1983, a broad understanding of spirituality had been unleashed from its roots in Roman Catholic monastic moorings [2], which provided a traditional bi-polar view of spirituality as: (i) the individual on a quest; (ii) to find her/his truest self in the context of reality [3]. This reality, or cosmic totality, may be God or some other Transcendent, a generic, secular term that had replaced God for some people by the end of the twentieth century [4]. A more recent shift in the understanding of spirituality was not instigated by the further inclusion of secular ideas into definitions of spirituality, but by a move from the dual structure (of personal quest, for an external reality) to an inward focus. The notion of the Self became paramount, with individual freedom and search for meaning becoming the whole focus of spirituality for many [4]. This focus is evident in the structure of numerous instruments designed to measure spirituality and spiritual health/well-being investigated by Fisher [5]. The most significant focus of these measures was on relationship with self, exceeding that of relationship with God, followed by relationship with others, with least emphasis on the environment.

Very few instruments contain equal numbers of items by which to assess these four domains of spirituality or spiritual health/well-being, namely relationships with self, others, environment and Transcendent Other (commonly called God). The Spiritual Health And Life-Orientation Measure (SHALOM), which was first reported in 1999 [6], is one such instrument. It has been sought for use in over 200 studies in 20 languages [7]. SHALOM has been thoroughly tested for its statistical validity [8-10]. Its 20 items are distributed evenly over four domains of spiritual well-being, and measures quality of relationships with oneself, with others, with the environment and/or with a Transcendent Other [7]. Simple language was selected to enable respondents to understand and probe complex constructs, as SHALOM was developed for use with secondary school students, in the belief that an instrument suitable for them would also be useful for adults. Consequently, the words 'God', 'Divine' and 'Creator' appeared in four of the five items used to assess the Transcendental domain of spiritual well-being, because notions such as 'higher power' and 'godlike force' were less comprehensible to the students [11].

Over the last nineteen years, participants in studies using SHALOM have made negligible comment on the instrument. However, a few challenges have been presented from a small minority, during the author's 46 conference presentations and workshops on spiritual well-being, in Australia and overseas, almost exclusively with westerners, except for work in Hong Kong. It is mainly 'academics' who have voiced concern that the current form of SHALOM favors people with theistic beliefs, because it includes the word 'God.' This criticism is not valid, because SHALOM employs a double-response method of comparing each person's ideals with their lived experience. So, if a person does not embrace a belief in any god, then there will be no dissonance when they score 'very low' (equivalent to negligible or none) on lived experience in this domain, as it will match their presumably 'very low' scores for their ideals relating to spiritual well-being. This function separates SHALOM from other instruments which can underrate people's spiritual well-being if they score low on lived experience in this area, in comparison with other people's scores. 
Three Australian converts to Buddhism and one American philosophy lecturer in Hong Kong questioned the use of the word 'God.' One American post-graduate student refused to look closely at SHALOM, and two more were refused permission to use it in their research, because of the God-word. Opposition by atheists on research and ethics committees had to be overcome on four occasions at the University of Ballarat, and Ballarat Health Services, in their attempts to eliminate the word 'God.' Ballarat is a regional city of just under 100,000 people. Universities and Health Services in nine larger Australian cities, as well as other American studies, have had no problems permitting the use of SHALOM for research. The word 'God' evokes emotive responses in many people, to the extent that one nurse educator in Ballarat tried to insist that it be written with a small ' $\mathrm{g}$ '.

Following a public lecture in Hong Kong, discussion with the Director of the Centre for Religious and Spirituality Education led to the idea of using the word 'Transcendent,' with a variety of meanings for people to choose from, as an alternative to 'God,' to see if it would better accommodate views held by adherents of religious traditions as well as non-religious. The word 'deity' had been used in a Chinese translation of SHALOM [12,13], although previous research with an English version of SHALOM among predominantly Buddhist Master of Nursing students in Hong Kong had not created any comment [14]. Subsequent email communication with the philosophy lecturer in Hong Kong placated his concerns when he was advised of the use of the word 'Transcendent.' A research student in Puerto Rico was also advised to change the word God to Transcendent in SHALOM, and provide six alternatives. This led to acceptance by her supervisors of her project, which they had previously opposed because of the God-word, even though Puerto Rico reports 95\% with theistic beliefs and only $2.3 \%$ non-religious in its population [15].

The most contentious issue in discussions of spiritual well-being relates to the question of a Transcendent Other (that is, some-One or some-Thing that exists beyond the human and natural worlds) having influence over humans. Worldviews and opinions are many, but empirical studies of them are few. Research needs to focus clearly on discussions of the Transcendent. To this end, the project being reported in this paper investigated whether replacing the words 'God,' 'Divine' and 'Creator' with the word 'Transcendent' would lead to as valid a spiritual well-being questionnaire as the original SHALOM has proven to be. If so, the modified SHALOM could be a more generic instrument, suitable for use with people embracing worldviews ranging from belief in God to disbelief in any Transcendent. Such a generic instrument would help overcome the difficulty many researchers have of ensuring they canvas all world-views impartially, without appearing to favor, or in fact favoring, one over others.

\section{Procedure}

\subsection{Instrument}

SHALOM comprises twenty items, with five in each of four domains, reflecting spiritual well-being (SWB), namely Personal SWB (with self-awareness providing the motivating force in relating with self in search for meaning, purpose and values in life); Communal SWB (in-depth inter-personal relationships with reference to morality, culture and religion [for those for whom it is important]); Environmental SWB (connecting with the environment beyond care nurture and stewardship thereof); 
Transcendental SWB (by faith relating with something or someone beyond the human and natural worlds).

Respondents were asked for two responses to each of the 20 items, to indicate the importance of each item for (i) their ideals for spiritual well-being, and (ii) their lived experiences. A 5-point Likert scale was used with a continuum from 'very low' (scored as 1) to 'very high' (scored as 5). The items for the original SHALOM are shown below. Using the word 'God' has worked well in many studies using SHALOM [7], as people were free to choose their own meaning for the word, just as they did for every other concept expressed therein, such as 'meaning in life', 'love of other people', 'connection with nature.' Their lived experience was measured against their ideals for spiritual well-being. In other words, each person was measured against themselves, so no absolute definition of terms is necessary, when using SHALOM.

\begin{tabular}{|c|c|}
\hline Personal SWB & Communal SWB \\
\hline Developing & Developing \\
\hline a sense of identity & a love of/for other people \\
\hline self-awareness & forgiveness toward others \\
\hline joy in life & trust between individuals \\
\hline inner peace & respect for others \\
\hline meaning in life & kindness toward other people \\
\hline Environmental SWB & Transcendental SWB \\
\hline Developing & Developing \\
\hline connection with nature & personal relationship with the Divine/God \\
\hline awe at a breathtaking view & worship of the Creator \\
\hline oneness with nature & oneness with God \\
\hline harmony with the environment & peace with God \\
\hline sense of 'magic' in the environment & prayer life \\
\hline
\end{tabular}

\subsection{Method}

With increasing interest in spirituality and well-being, especially over the last 30 years, numerous quantitative surveys have been developed [5,16-19]. Of these many instruments, recent evidence has been presented to show that the spiritual well-being questionnaire, called SHALOM, is considered the best [20], or most promising [21], of all available spiritual well-being measures. That notwithstanding, in light of the claim of theistic bias levelled at the existing SHALOM, four of the five original Transcendental factor items had the words 'God,' 'Divine' and 'Creator' replaced by the word 'Transcendent.' In the revised version, respondents were presented with the statement, 'When people believe their lives are influenced by SomeOne or SomeThing beyond the human and natural worlds, they use different words. Please choose one of the following to show what best describes the supernatural influence in your life.' Eighteen alternatives were provided, namely Allah, Angel/s, Buddha, Deceased person, Deity/deities, Divine, Fate, Father God, Gaia, God, Heaven, Higher power, Higher self, Mystery, Otherness, Presence, Something there, Universe/universal spirit' together with 'Not an area in which I believe.' As the focus in this study was on spiritual well-being [italics for 
emphasis], consideration was not given to possible negative influences by demons or the occult on people.

The following comments were also placed on the survey, 'What you have chosen can be called the Transcendent influence on your life. Please keep this interpretation in mind when you see the term Transcendent in the questions that follow.'

Six hundred people, who had published papers on spirituality that had been accessed by the author, were sent an email invitation to complete an online survey (http://tinyurl.com/swbfisher), comprising the revised 20-item SHALOM, together with questions on demographics and background beliefs. The survey was also advertised among members of the International Association for Children's Spirituality, the International Seminar on Religious Education and Values, the Parliament of the World's Religions and was promoted by the Director of the Centre for Religious and Spirituality Education in Hong Kong, as well as amongst people who are not likely to believe in the supernatural/Transcendent, namely in the Atheist Foundation of Australia, via their web Forum. It was anticipated that the survey would take 10 to 15 minutes to complete. Potential participants were also asked to let others know about the survey, in an effort to extend the sample size using a snow-ball technique.

Data, collected using the LimeSurvey technique, were subjected to basic statistical and maximum likelihood confirmatory factor analyses using SPSS (Statistical Product and Service Solutions) and AMOS (Analysis of Moment Structures). These results, and those from previous studies employing similar statistical techniques, were used to compare the usefulness of the revised and original versions of SHALOM in measuring and explaining relationships in each of four domains of spiritual well-being, with particular emphasis on the Transcendental domain of spiritual well-being.

\section{Results and Discussion}

\subsection{Participants}

A total of 409 completed web-surveys were received from people in 14 geographic regions (Australia/New Zealand 62, Pacific OECD 3, Central Asia/China 24, Southern Asia 37, Middle East/North Africa 9, Saharan Africa 8, Southern Europe 5, Central Europe 31, Western Europe 46, former Soviet Union 51, UK 56, North America 69, Central America 1, South America 7). Fifty six percent of these were in direct response to a written invitation from the author, $40 \%$ by referred invitation, and $4 \%$ by direct access to the survey on the web. Females comprised $59 \%$ of the cohort (mean age 38.8 years, SD = 15.1), with $41 \%$ males (mean age 45.7 years, SD = 17.1). English was not the primary language spoken for $52.3 \%$ of the respondents. Sixty-five percent were either married (58\%) or had been married (6\% divorced/separated, 1\% widowed).

The education level of the respondents exceeded that of the general population with $64 \%$ claiming a post-graduate degree, $8 \%$ a post-graduate diploma and $16 \%$ an undergraduate degree. The majority were professionals working with people (78\%) and technology (9\%) or were managers (8\%). A wide range of worldviews was held by participants (agnostic 21, atheist 26, Baha'i 1, Buddhism 28, Catholic/Orthodox Christianity 110, Protestant Christianity 137, Christian Science 10, environmentalism 6, existentialism 5, Hari Krishna 1, Hindu 5, humanism 9, Islam 24, Judaism 10, Jehovah’s Witness 1, native spirituality 4, Shinto 2, Tao 5, Wicca 2, Zoroastrianism 1). In short $18 \%$ claimed no religious 
affiliation, 27\% Catholic, 33\% Protestant, 22\% other religions. A broad range of views was also shown on the description of a Transcendent influencing the participants (Allah 23, Angel/s 11, Buddha 6, Deceased person 2, Deity/deities 5, the Divine 11, Fate 21, Father God 58, Gaia 1, God 150, Higher power 23, Higher Self 9, Mystery 10, Otherness 5, Presence 13, Something there 6, Universe/universal spirit 16; Not an area believed in 39).

\subsection{Comparison Groups}

As the respondents to the web-survey were more educated than the general population, a similarly-sized sample of university students and staff was selected from respondents in previous studies, which used the original SHALOM [22,23]. This sample was made up of 378 older students and staff in an Australian public university (see Table 1 for details). Another sample, comprised of 460 secondary school students, aged 12 to 18 years (mean $=15.3$, SD =1.7), among whom SHALOM was originally developed, in Years 7 to 12 in State, Catholic, Christian Community and other independent schools in Victoria, Australia [11].

Table 1. Distribution of samples in three studies with the SHALOM.

\begin{tabular}{l|l|l|lllll|llll}
\hline & & $\mathrm{F}$ & \multicolumn{5}{|c|}{ Age } & $\%$ & \multicolumn{4}{|c}{ Religious affiliation \% } \\
Group & $\mathrm{n}$ & $\%$ & $<20$ & $20 \mathrm{~s}$ & 30s & 40s & $50+$ & none & Cath. & Prot. & other \\
\hline Sec school & 460 & 49 & 100 & & & & & 22 & 26 & 50 & 2 \\
Uni stu staff & 378 & 72 & & 53 & 15 & 18 & 13 & 40 & 27 & 30 & 3 \\
Web survey & 409 & 59 & 3 & 27 & 18 & 16 & 36 & 18 & 27 & 33 & 12 \\
\hline
\end{tabular}

\subsection{Psychometric Properties of the Revised, Generic SHALOM, and Comparison with the Original}

Principal component analysis (PCA) of responses from the web survey of the lived experience component of the revised SHALOM revealed the presence of four components, which explained $72.5 \%$ of total variance. All the variables loaded onto the appropriate scales revealing sound measures for Personal, Communal, Environmental and (modified) Transcendental domains of spiritual well-being. Reliability analyses of the scales yielded good Cronbach's á-coefficients, with the Transcendental domain yielding a very good value of .95 (for details see Table 2).

When subjected to principal components analysis, these four domains cohered into a single higher-order factor, called spiritual well-being (SWB) (Kaiser-Meyer-Olkin value $=.74,63.8 \%$ total variance explained). As spiritual well-being is made up of these four domains, linear regression analysis was performed to determine the relative contribution made by each of them to the whole. At .42, the â-value for Transcendental SWB far exceeded the others (Personal SWB .27, Communal SWB .25 , Environmental SWB .33), indicating that Transcendental spiritual well-being explained greatest variance in spiritual well-being overall. This finding parallels those of the original SHALOM, which concluded that relating with God is shown to be most important for spiritual well-being [11,24].

Confirmatory factor analyses (CFA) were performed using AMOS to investigate the relative construct validity of the original and modified versions of SHALOM, with their four component factors. As there is not a sole appropriate test, a range of fit indices was selected to test the CFA models to see which best represents the data sets. Absolute fit indices were the relative Chi-square 
( $\times^{2} / \mathrm{df}$ ), Akaike's Information Criterion (AIC), and the Expected Cross-Validation Index (ECVI). Relative Fit Indices were the Incremental Fit Index (IFI), Normed Fit Index (NFI) and Tucker-Lewis Index (TLI). The Parsimonious Normed Fit Index (PNFI) was used. Noncentrality-based Indices were the Root Mean Square Error Approximation (RMSEA) and the Comparative Fit Index (CFI). The target values to indicate good fit indices are listed in the bottom row of Table $3[25,26]$.

Table 2. Pattern matrix for PCA with Oblimin Rotation of 4-factor solution of generic SHALOM items, together with Cronbach’s alpha coefficient for reliability analyses of scales.

\begin{tabular}{|c|c|c|c|c|}
\hline Item & Com SWB & Tra SWB & Env SWB & Per SWB \\
\hline Identity & & & & .88 \\
\hline Self-awareness & & & & .82 \\
\hline Joy & & & & .40 \\
\hline Inner peace & & & & .41 \\
\hline Meaning & & & & .40 \\
\hline Love others & .77 & & & \\
\hline Forgive others & .79 & & & \\
\hline Trust & .68 & & & \\
\hline Respect others & .79 & & & \\
\hline Kindness & .83 & & & \\
\hline Connect with nature & & & .79 & \\
\hline Awe at view & & & .62 & \\
\hline One with nature & & & .92 & \\
\hline Harmony with environment & & & .79 & \\
\hline 'magic' in environment & & & .80 & \\
\hline Relation with Transcendent & & .92 & & \\
\hline Worship Transcendent & & .90 & & \\
\hline One with Transcendent & & .86 & & \\
\hline Peace with Transcendent & & .89 & & \\
\hline Prayer life & & .88 & & \\
\hline Eigenvalue (\% variance) & $8.93(44.7 \%)$ & $2.78(13.9 \%)$ & $1.87(9.3 \%)$ & $1.00(4.6 \%)$ \\
\hline alpha value & .88 & .95 & .87 & .86 \\
\hline mean(SD) & $4.02(.74)$ & 3.33(1.25) & 3.32(.98) & 3.98(.78) \\
\hline
\end{tabular}

NB. Per SWB = Personal spiritual well-being, Com = Communal, Env $=$ Environmental, Tra $=$ Transcendental. Only values .40 and above are recorded.

Values of fit indices for the lived experience component of the modified version of SHALOM displayed borderline acceptability, for relative Chi-square (with $x^{2} / \mathrm{df}>3.5$, where values below 2 are good, those between 2 and 3 are generally considered acceptable, with some people accepting up to 5) and RMSEA (value of .078, which is just below the normally accepted upper limit of .08). The two cohorts that were tested using the original version of SHALOM, employing the term 'God', displayed acceptable to good values on the fit indices investigated. Despite considerable differences in age and world-views, especially religious aspects, between the secondary school and university cohorts studied, their fit indices for the original SHALOM were markedly similar, indicating the consistency of this instrument as a measure of spiritual well-being. Although the modified, more generic form of 
SHALOM, using the term Transcendent, is an acceptable measure of spiritual well-being, it is not as good as the original, which employs the term God in the measure of Transcendental SWB (see Table 3).

Table 3. Summary results for confirmatory factor analyses of versions of SHALOM.

\begin{tabular}{l|c|ccccccccc}
\hline $\begin{array}{l}\text { Version of } \\
\text { SHALOM }\end{array}$ & $\mathrm{n}$ & $\mathrm{x}^{2} / \mathrm{df}$ & AIC & ECVI & IFI & NFI & TLI & PNFI & RMSEA & CFI \\
\hline Uni. & 378 & 2.70 & 574 & 1.51 & .944 & .914 & .935 & .79 & .067 & .944 \\
Sec. stu. & 460 & 2.70 & 575 & 1.25 & .941 & .909 & .931 & .79 & .061 & .940 \\
Generic & 409 & 3.51 & 668 & 1.64 & .931 & .906 & .920 & .78 & .078 & .931 \\
\hline \multicolumn{1}{c}{ perT } & 231 & 2.97 & 620 & 2.70 & .899 & .855 & .882 & .74 & .093 & .898 \\
$\quad$ impT & 139 & 1.66 & 404 & 2.93 & .940 & .882 & .930 & .74 & .069 & .939 \\
\hline gd value & & $<2-3$ & lowest & lowest & $>.90$ & $>.90$ & $>.90$ & $>.50$ & $<.05-.08$ & $>.93$ \\
\hline
\end{tabular}

NB Uni. = university students \& staff; sec. stu = secondary school students; perT $=$ personal Transcendent; $\mathrm{impT}=$ impersonal Transcendent; gd = good; $x^{2} / \mathrm{df}=$ relative Chi-square, AIC = Akaike's Information Criterion, ECVI $=$ Expected Cross-Validation Index, IFI $=$ Incremental Fit Index, NFI $=$ Normed Fit Index, TLI $=$ Tucker-Lewis Index, PNFI $=$ Parsimonious Normed Fit Index, RMSEA = Root Mean Square Error Approximation (RMSEA), CFI = Comparative Fit Index.

The sample in this study was split by views on the Transcendent, into personal (e.g., Allah, God, etc) and impersonal (e.g., higher power, something there, etc). Acceptable values for fit indices were obtained for those choosing impersonal Transcendent, but less than satisfactory values for those embracing a personal Transcendent (see Table 3). The 39 respondents who indicated non-belief in such an entity were omitted from this study of subsets as the small number did not permit appropriate statistical calculations.

\subsection{Comparing Spiritual Dissonance in Versions of SHALOM}

SHALOM actually comprises two spiritual well-being measures. The Spiritual Health Measure (SHM) is the lived experience component discussed above, whereas the (Spiritual) Life-Orientation Measure (LOM) comprises the ideals for spiritual well-being held by respondents. Together they make the Spiritual Health And Life-Orientation Measure (SHALOM). The difference in score between the ideals and lived experiences reveals the level of dissonance or harmony in each domain of spiritual well-being. This double-response method has been shown to provide a better assessment of the quality of relationships reflecting each of four domains of spiritual well-being, in comparison with lived experiences only [11]. Comparing values of fit indices in Tables 3 and 4 for the university and secondary school cohorts reveals similar results, with the dissonance method generally providing better fit indices.

The fit indices for the dissonance scores on the generic form of SHALOM show acceptability for the instrument as a whole and for the impersonal Transcendent group in particular (see Table 4). However, the dissonance values for those embracing a personal Transcendent did not yield an acceptable model, similar to the results using lived experience only (shown in Table 3). Therefore, it can be concluded that using the word 'God' is more acceptable to these people than 'Transcendent'. 
Table 4. Summary of CFA for dissonance values in versions of SHALOM.

\begin{tabular}{l|c|ccccccccc}
\hline $\begin{array}{l}\text { Version of } \\
\text { SHALOM }\end{array}$ & $\mathrm{n}$ & $\mathrm{x}^{2} / \mathrm{df}$ & AIC & ECVI & IFI & NFI & TLI & PNFI & RMSEA & CFI \\
\hline dUni. & 378 & 2.63 & 524 & 1.39 & .907 & .859 & .892 & .74 & .066 & .906 \\
dSec. stu. & 460 & 1.97 & 415 & .91 & .950 & .903 & .941 & .78 & .046 & .949 \\
dGeneric & 409 & 2.81 & 553 & 1.36 & .896 & .847 & .878 & .73 & .067 & .895 \\
\hline \multicolumn{1}{c}{ dperT } & 231 & 2.89 & 605 & 2.63 & .808 & .734 & .774 & .63 & .091 & .805 \\
$\quad$ dimpT & 139 & 1.56 & 387 & 2.81 & .909 & .782 & .892 & .68 & .064 & .907 \\
\hline gd value & & $<2-3$ & lowest & lowest & $>.90$ & $>.90$ & $>.90$ & $>.50$ & $<.05-.08$ & $>.93$ \\
\hline
\end{tabular}

NB Uni. = university students \& staff; sec. stu = secondary school students; perT $=$ personal Transcendent; impT = impersonal Transcendent; $\mathrm{d}$ = dissonance.

\section{Conclusions}

Four of the five items in the Transcendental domain of the original Spiritual Health And Life-Orientation Measure (SHALOM) were adjusted by replacing the words 'God, 'Divine' and 'Creator' with the word 'Transcendent.' Before completing the 20-items on the revised SHALOM in a web survey, respondents who had previously expressed interest in spirituality, or a likely aversion to it, were asked to indicate their description of any Transcendent influence on their lives, or if they did not believe in such an entity. Confirmatory factor analysis revealed that the modified, generic form of SHALOM showed acceptable model fit, comprising four clearly delineated domains of spiritual well-being. Of particular interest was the finding that the modified Transcendental domain of spiritual well-being holds together well statistically and provides the greatest explanation of variance in spiritual well-being overall. This modified SHALOM can be employed in future studies as a generic measure of spiritual well-being across a variety of worldviews. However, the nature of the cohort under investigation should determine which version of SHALOM is used, not the worldview of the investigators.

It should also be kept in mind that the model fit for the more generic version of SHALOM was not as good as that for the original, when it was compared with a select sample of university students and staff, and a cohort of secondary school students. This study, of the generic version of SHALOM, only had limited numbers of well-educated people in each category relating with alternative Transcendents for their spiritual well-being. Therefore further studies with more people are warranted to gain adequate sample sizes to see how well each version of SHALOM fares in general populations with varying world-views. Overall, the tentative conclusion that can be drawn from this study is that, rather than investigating relationship with a Transcendent, you can't beat relating with God for spiritual well-being.

\section{Acknowledgements}

Sincere thanks are expressed for the people who responded to the web survey.

\section{Conflict of Interest}

The author declares no conflict of interest. 


\section{References}

1. National Interfaith Coalition on Aging. Spiritual Well-Being: A Definition. Athens, GA.: Author, 1975.

2. Walter Principe. “Toward defining spirituality.” Studies in Religion 12 (1983): 127-41.

3. Peter H. Van Ness. Spirituality and the Secular Quest. New York: Crossroad Publishing Co., 1996.

4. Lucy Bregman. "Spirituality definitions: A moving target.” In Spirituality: Theory, Praxis and Pedagogy. Edited by Martin Fowler, John D. Martin III, and John L. Hochheimer. Oxford, UK: Inter-Disciplinary Press, 2012, 4-10.

5. John W. Fisher. "Reaching the heart: Assessing and nurturing spiritual well-being via education." EdD dissertation, University of Ballarat, Victoria, Australia, 2009. Available online: http://archimedes.ballarat.edu.au:8080/vital/access/HandleResolver/1959.17/13481 (accessed on 10 January 2013).

6. John W. Fisher. "Developing a Spiritual Health And Life-Orientation Measure for secondary school students." In Research with a Regional/Rural Focus: Proceedings of the University of Ballarat Inaugural Annual Research Conference. Edited by Janette Ryan, Vivienne Wittwer and Peter Baird. Ballarat: University of Ballarat, Research and Graduate Studies Office, 1999, 57-63.

7. John Fisher. "Development and application of a spiritual well-being questionnaire called SHALOM.” Religions 1 (2010): 105-21.

8. Rapson Gomez, and John W. Fisher. "Domains of spiritual well-being and development and validation of the Spiritual Well-Being Questionnaire.” Personality \& Individual Differences 35 (2003): 1975-91.

9. Rapson Gomez, and John W. Fisher. "Item Response Theory analysis of the Spiritual Well-Being Questionnaire.” Personality \& Individual Differences 38 (2005): 1107-21.

10. Rapson Gomez, and John W. Fisher. “The Spiritual Well-Being Questionnaire: Testing for model applicability, measurement and structural equivalencies and latent mean differences across gender.” Personality \& Individual Differences 39 (2005): 1383-93.

11. John W. Fisher. "Assessing spiritual well-being: Relating with God explains greatest variance in spiritual well-being among Australian youth.” International Journal of Children's Spirituality (under review).

12. Irene Mok. "A study of the spiritual health of adolescents in three Hong Kong secondary schools.” EdD thesis, Hong Kong Institute of Education, 2013.

13. John W. Fisher, and Ping Ho Wong. "Comparing levels of spiritual well-being and support among pre-service teachers in Hong Kong and Australia.” Religious Education Journal of Australia 29 (2013): 34-40.

14. John W. Fisher. "Enhancing university students' spiritual well-being.” In Research for a Better Community: Proceedings of the University of Ballarat Second Annual Research Conference, 8 September 2000. Edited by Janette Ryan and Peter Baird. Ballarat: University of Ballarat, Research and Graduate Studies Office, 2002, 58-61.

15. Magaly Rivera. “Welcome to Puerto Rico.” 2013. Available online: http://www.topuertorico.org/ people.shtml (accessed on 24 June 2013). 
16. Peter C. Hill, and Ralph W. Hood. Measures of Religiosity. Birmingham, AL: Religious Education Press, 1999.

17. Douglas A. MacDonald, Jeffrey G. Kuentzel, and H.L. Friedman. "A survey of measures of transpersonal constructs. Part II - Additional instruments.” Journal of Transpersonal Psychology 31 (1999): 155-77.

18. Harold G. Koenig, Michael E. McCullough, and David B. Larson. Handbook of Religion and Health. Oxford, UK: Oxford University Press, 2001.

19. Bella Vivat. "Measures of spiritual issues for palliative care patients: A literature review." Palliative Medicine 22 (2008): 859-68.

20. Trevor Moodley. "The relationship between coping and spiritual well-being during adolescence.” PhD dissertation, Department of Psychology, University of the Free State, Bloemfontein, South Africa, 2008.

21. Eltica de J. Meezenbroek, Bert Garssen, Machteld van den Berg, and Dirk van Dierendonck. et al. "Measuring spirituality as a universal human experience: A review of spirituality questionnaires." Journal of Religion \& Health 51 (2012): 336-54.

22. John W. Fisher, and Eileen T. Sellers. "Quality of life in the workplace: spirituality, meaning and purpose." Refereed paper in The Proceedings of the $3^{\text {rd }}$ Annual Conference on Spirituality, Leadership and Management. Ballarat, Australia: University of Ballarat, 2000, 14-19.

23. John W. Fisher. "Investigating Australian education students' views about spiritual well-being as compared with teachers in schools.” International Journal of Children's Spirituality 14 (2009): 151-67.

24. John W. Fisher. “The importance of relating with God for spiritual well-being.” In Spirituality: New Reflections on Theory, Praxis \& Pedagogy. Edited by Martin C. Fowler, Michael Weiss, and John L. Hochheimer. Oxford, UK: Inter Disciplinary Press, 2012, 147-61.

25. Simon Moss. "Fit indices for structural equation modelling.” Psychlopedia, 2009. Available online: http://www.psych-it.com.au/Psychlopedia/article.asp?id=277 (accessed on 3 April 2013).

26. Lawrence S. Meyers, Glenn Gamst, and A.J. Guarino. Applied multivariate research: Design and interpretation, $2^{\text {nd }}$ ed. Thousand Oaks, CA: Sage Publications, 2013.

(C) 2013 by the author; licensee MDPI, Basel, Switzerland. This article is an open access article distributed under the terms and conditions of the Creative Commons Attribution license (http://creativecommons.org/licenses/by/3.0/). 